\title{
Identifying Health Care Environment Contradictions in Terms of Infection Control during a Pandemic with a Focus on Health Workers' Experience
}

\author{
Maryam Lesan ${ }^{1} \mathbb{D}$, Fatemeh Khozaei ${ }^{2, *}$, Mi Jeong Kim ${ }^{3, *} \mathbb{1}$ and Marziyeh Shahidi Nejad ${ }^{2}$ \\ 1 Department of Architecture, School of Civil Engineering, Babol Noshirvani University of Technology, \\ Babol 4714871167, Iran; m.lesan@nit.ac.ir \\ 2 Department of Architecture, Islamic Azad University, Kerman Branch, Kerman 7635131167, Iran; \\ mzshahidinejad@gmail.com \\ 3 School of Architecture, Hanyang University, Seoul 04763, Korea \\ * Correspondence: Fkhozaei@iauk.ac.ir (F.K.); mijeongkim@hanyang.ac.kr (M.J.K.)
}

check for

updates

Citation: Lesan, M.; Khozaei, F.; Kim, M.J.; Shahidi Nejad, M. Identifying Health Care Environment

Contradictions in Terms of Infection Control during a Pandemic with a Focus on Health Workers' Experience. Sustainability 2021, 13, 9964. https:// doi.org/10.3390/su13179964

Academic Editors: Alan Randall and Nikos A. Salingaros

Received: 12 June 2021

Accepted: 18 August 2021

Published: 6 September 2021

Publisher's Note: MDPI stays neutral with regard to jurisdictional claims in published maps and institutional affiliations.

Copyright: (c) 2021 by the authors. Licensee MDPI, Basel, Switzerland. This article is an open access article distributed under the terms and conditions of the Creative Commons Attribution (CC BY) license (https:/ / creativecommons.org/licenses/by/ $4.0 /)$.

\begin{abstract}
During the past year, health care environments have struggled to cope with the various impacts of COVID-19 around the world. Health care facilities need to help strengthen resistance to pathogen threats and provide care for patients and health workers in the safest possible way. Architectural design strategies can play a significant role in infection prevention and control. The current study aims to examine the experiences of health workers with hospital spaces during the COVID-19 pandemic. Identifying the difficulties they face, the present study attempts to shed light on the role of the health care layout configuration in combating pandemics. The authors conducted observations at four hospitals and a series of online semi-structured interviews with 162 health care staff from March to May 2020. The study indicated that space configuration and the hospitalization of patients, layout and circulation of the environment, operation services such as indoor environment conditions, maintenance of health care system, and organizational support for health care staff were the most critical factors affecting infection control in health care environments. The initial zoning and separation of patients were the most effective methods of controlling infection. Hospitals with clustered plan layouts were found to be the most effective buildings for the zoning of COVID-19 patients during the pandemic and for infection control.
\end{abstract}

Keywords: COVID-19; hospital; health care facilities; built environment; infection control

\section{Introduction}

During the past year, health care environments have struggled to cope with the various impacts of COVID-19 around the world. Health care facilities need to help strengthen resistance to pathogen threats and provide care for patients and health care workers in the safest possible way. Architectural design strategies can play a significant role in infection prevention and control. The current study aims to examine the experiences of health care workers with hospital spaces during the COVID-19 pandemic. When a novel coronavirus was reported in China in 2019, health care systems worldwide could not predict how it would affect public health globally. Today, more than one year from the appearance of the COVID-19 pandemic, we have a more progressive outlook over the danger of such a disease. The importance of infection control has always been crucial in health care environments, but it becomes even more critical during pandemics such as the COVID-19 pandemic.

Various factors affect infection distribution in health care centers. A single cough in an indoor health care environment can generate hundreds of droplets, and a single sneeze can generate thousands (up to 40,000) at speeds of up to 50-200 miles per hour, with each droplet containing millions of viral particles [1]. Hospitals are environments 
where infectious droplets can be particularly hazardous since hospitalized patients are often prone to infection due to preexisting illnesses [1].

For effective infection control in health care settings, it is essential to realize how viruses are transmitted. As such, under different circumstances, information will affect the choice of infection control measures in health care environments. Infected patients discharge infectious droplets through breathing, coughing, or sneezing [2]. According to the Centers for Disease Control and Prevention, infection with respiratory viruses in health care environments is principally transmitted through three general modes: contact, droplet, and airborne.

Contact transmission is spread through direct contact with an infected person (e.g., touching during a handshake) or a contaminated artifact or surface. The latter is sometimes referred to as "fomite transmission."

Droplet transmission is spread through exposure to virus-containing respiratory droplets (i.e., larger and smaller droplets and particles) exhaled by an infectious person. Transmission is most likely to occur when someone is close to the contagious person, generally within about 6 feet.

Airborne transmission is spread through exposure to those virus-containing respiratory droplets containing smaller droplets and particles that can persist while suspended in the air over long distances (usually greater than 6 feet) and time (typically hours) [3].

Even though the repeated sanitization of health care centers can reduce the incidence risk of acquired infection, improper space management can increase the risk of infectious disease transmission. Environmental designs have proved to affect infection control in health care centers. The literature suggests that the design of the physical environment strongly impacts hospital-acquired infection rates by affecting both airborne and contact transmission routes $[4,5]$. As most health care centers were designed and constructed with minimum knowledge of the new emerging infectious diseases of our century, such as COVID-19, adopting a holistic view in the design and management of health care centers for critical pandemic situations is essential. There is a need to understand the problems and environmental contradictions of current health care design regarding infection control to design better health care facilities in the future,

The purpose of this research is to highlight the role of environmental design on infection control, focusing on the experiences of health care workers during the COVID-19 pandemic. The importance of the current study can be explained from various perspectives. First, in the last few years, several studies have evaluated various aspects of hospitals. Some of these studies have concentrated on plan configuration and design using observations or space syntax methodology. Space syntax is a valuable methodology for analyzing the spatial layouts and patterns of human activity in buildings and urban spaces. It provides quantitative analyses of individual spaces and the entire layout by using clear sightlines [6]. In his proposed model of system accidents, Rearson suggested that hospital design may impact patient safety, directly or indirectly, relating to both active or latent failure [4]. Studies indicate that aspects of health care design that directly impact patient safety include air quality, lighting, patient room design, and other interior design elements such as surface materials [7]. The second group of studies focused on the experiences of patients and health care staff with health care environments, shedding light on the positive and negative aspects of space. The majority of these studies were conducted during typical everyday situations and not during pandemics. Hence, the current study attempts to fill a part of this gap. The knowledge of the frontline staff can influence policy implementation during pandemics. Second, studies suggest that health care workers may experience a considerable amount of mental pressure during pandemics. Inappropriate working conditions (high workload and sudden increase in referrals) besides the stressful and high-risk working environment during the outbreak are among the most significant barriers to implementing COVID-19 policies in Iran [8]. Proper hospital design can reduce some of such tensions among health care staff. The results of the current study can provide 
great information for architects, hospital managers, and policy makers to bring more relief to health care workers during pandemics.

\section{Related Work}

Studies suggest factors such as fear of contagion, concern for family health, quarantine and interpersonal isolation, and trust in organizational support as influencing the behavior of health care staff during epidemics [9]. Recent research from several countries during the COVID-19 pandemic also has reported fatigue, distress, stress, and anxiety among health care staff [10-13]. Moreover, health care staff and nurses affect patient care experiences due to the time that they spend with patients [14]. Other studies show a positive correlation between the positive nursing care experiences that patients have and good and healthy work environments [15-17]. However, the problems that health care workers may face during the COVID-19 pandemic may hinder them from caring for the infected patients [18]. There is an agreement that health care environments can reduce the amount of tension and stress health care workers face on a daily basis. Proper hospital design and management that decreases the chance of infection distribution can bring more relief to health care workers. Accordingly, conducting this research is highly important and is of great value.

\subsection{Design Attributes and Infection Control}

Various environmental design attributes have been found to affect infection control in health care spaces. Ulrich [5], for example, found that single rooms have advantages over multi-bed rooms, as they reduce airborne transmission cross-infection from airborne or aerosol droplet diseases. On the other hand, multi-bed rooms create a potential added risk for airborne transmission [5]. Ensuite toilets in single rooms, compared to shared bathrooms, are considered effective in containing outbreaks [5]. Moreover, studies suggest that many surfaces close to infected patients become contaminated in hospitals, and staff gloves and hands may become infected through contact transmission $[19,20]$. This type of transmission is more common in multi-bed units [21]. Although not specific to infection control, several studies focus on the design attributes and layouts of health care environments in order to make them more effective. In this regard, Pangrazio [22] and Jiang and Verdeber studied the impacts of circulation zones in health care settings on user perceptions and experiences and suggested that such spaces could impact the positive perceptions of patients towards their overall satisfaction with health care facilities [23].

In particular, poor design in health care environments can negatively impact staff outcomes such as staff stress, fatigue, annoyance, burnout, and lack of hand-washing compliance, leading to accidents and errors [7]. Dedicating spaces for working, resting, changing, and storage is a critical factor influencing staff satisfaction [24]. In emergencies, spaces that facilitate staff relaxation from psychological stress and work pressures could positively impact staff work performance [25]. The visual environment provides essential health benefits for patients [26] and impacts staff satisfaction [27]. For example, window views to nature can improve patient recovery time and can reduce the stress levels among nurses [24,28]. In addition to being a natural disinfectant, access to daylight also seems to significantly impact patients and staff, affecting their visual comfort [20]. More recent studies have shown that intrinsic features of glass such as transparency and brittleness are also responsible for subjective feelings that can affect the overall psychological comfort of building users [29].

\subsection{Operation Strategies and Infection Control}

A handful of studies suggest that health care-associated infection rates are lower when the air quality is very good [5]. Air flow may transport infections, and there is a need to manage high-risk patients separately from other patients [30]. Factors affecting ventilation in hospitals include room air changes per hour, the direction of the airflow and the air pressure, the type of air filter, the humidity, and ventilation system cleaning and maintenance [31]. For example, a study of health care staff in 17 Canadian hospitals showed 
a strong correlation between the risk of acquiring tuberculosis and exposure to patients in rooms with poor air quality and low air exchange rates but not with the ventilation of respiratory isolation rooms [32].

Infections and cleanliness are related to hygiene in health care environments, and the materials used in a hospital can have positive or negative effects on hygiene. For example, Anderson et al. [33] found higher amounts of microorganisms on carpeted floors than on bare floors. Noskin et al. [34] studied fabric-covered furniture and vinyl-covered furniture and vinyl surfaces contaminated with vancomycin-resistant enterocci (VRE). They suggested that vinyl also became contaminated. Therefore, the proper disinfection of inanimate surfaces is known as an effective measure in reducing the number of hospitalacquired infections [30,35].

Alcohol-based hand-rub dispensers and accessible hand-washing sinks are also known to lower hospital-acquired infection rates [35]. Studies suggest that hand-washing compliance is often insufficient (rarely reaching $45-50 \%$ ) [36] and is consistently lower in units with high bed occupancy rates [5]. Evidence advises placing sinks and alcohol/gel dispensers near staff movement paths in visually prominent locations near work points, which improves hand-washing compliance by $28 \%$ [37].

Daylight is an excellent bactericidal factor and can inhibit infection [30,38]. Studies suggest that sunlight can kill various bacteria such as anthrax, tuberculosis, etc. [39]. More recent research by Strong [40] indicates that diffused daylight over two layers of glass from a north window is highly effective in killing hemolytic streptococci within thirteen days. In contrast, a similar strain survived for 195 days in the dark in the same room.

\section{Materials and Methods}

In this study, we attempted to shed light on health care environment contradictions in terms of infection control during a pandemic while focusing on the experiences of health care workers. In the battle against COVID-19, frontline hospital staff are in direct contact with patients and have a better understanding of the shortcomings of health care environments. The current study applied an evidence-based design approach. Nowadays, health care design is increasingly guided by rigorous research linking the physical environment of hospitals to patient and staff outcomes. Health care design is moving toward "evidence-based design" to enhance design decisions for a planned environment [41,42]. EBD in health care environments indicates a significant relationship between the built environment and health-related outcomes. These include the reduction of medical errors (including nosocomial/ hospital-acquired infections), the reduction of stress (and injuries) on the medical staff, and improved patients healing [24,36,42].

The research methodology was qualitative and was based on the grounded theory, where researchers begin with an area of study and allow the theory to emerge from the data [43].

We conducted a series of interviews with the nursing staff and physicians from four public and private hospitals in Kerman (namely: Afzalipour, Payambar Azam, Mehregan, Bahonar), Iran (Figure 1). Among them, only Mehregan hospital was private. These hospitals were chosen for this research because they used to admit COVID-19 patients during a certain period. Currently, all COVID-19 patients are admitted to Afzalipour Hospital.

Data were collected from March to May 2020. Due to the large number of patients affected by the pandemic, there was no specific hospital for admitting these patients, and they were distributed among different public and private hospitals. All four hospital plans were different in terms of layout, space configuration, and the number of floors. The selected hospitals are representative of typical hospital plans in Iran. Bahonar Hospital (A) has several single and double-story linear plan buildings scattered in the hospital yard, Afzalipour Hospital (B) shares a multi-story clustered plan, Mehregan Hospital (C) is a linear multi-story building, and Payambar Azam Hospital (D) covers a square multi-story plan. Figure 2 shows the layouts of the selected hospitals in Kerman. 
The semi-structured interview was designed as a flexible and broad survey. In general, the interviews comprised two sections. The first section recorded demographic information such as the participant's age, gender, occupation (doctor or nurse), and years of experience in the health care environment. In the second section, participants were queried about the main problems and causes of infection distribution during the pandemic and how the physical environment has exacerbated the condition for them. The participants were asked to answer the following questions: (1) How do you evaluate the appropriateness of your hospital design in terms of admitting COVID-19 patients? (2) In your opinion, what design or management attributes of your hospital affect the distribution of infection in the hospital? (3) What are difficulties you have faced in the hospital during the COVID-19 pandemic?

The interviews were conducted with 162 health care workers who were highly engaged in the process, who perceived the danger of the virus, and who were working in a hospital not initially designed for a pandemic. Respondents were selected to participate in the survey by stratified random sampling. All participants were over 18 years of age and were informed that the study was voluntary and that their data would be kept confidential. In-depth, semi-structured interviews with frontline staff were conducted over WhatsApp from March to May 2020, and audio was recorded with the consent of the participants. Interviews lasted between 20 to $30 \mathrm{~min}$. The interviews were recorded and transcribed for further analysis. All of the transcripts were then thematically analyzed with a coding approach by applying Ulrich's [44] (and Brambilla et al. [24]) evidence-based design (EBD) framework. Figure 2 shows the proposed framework of the study.

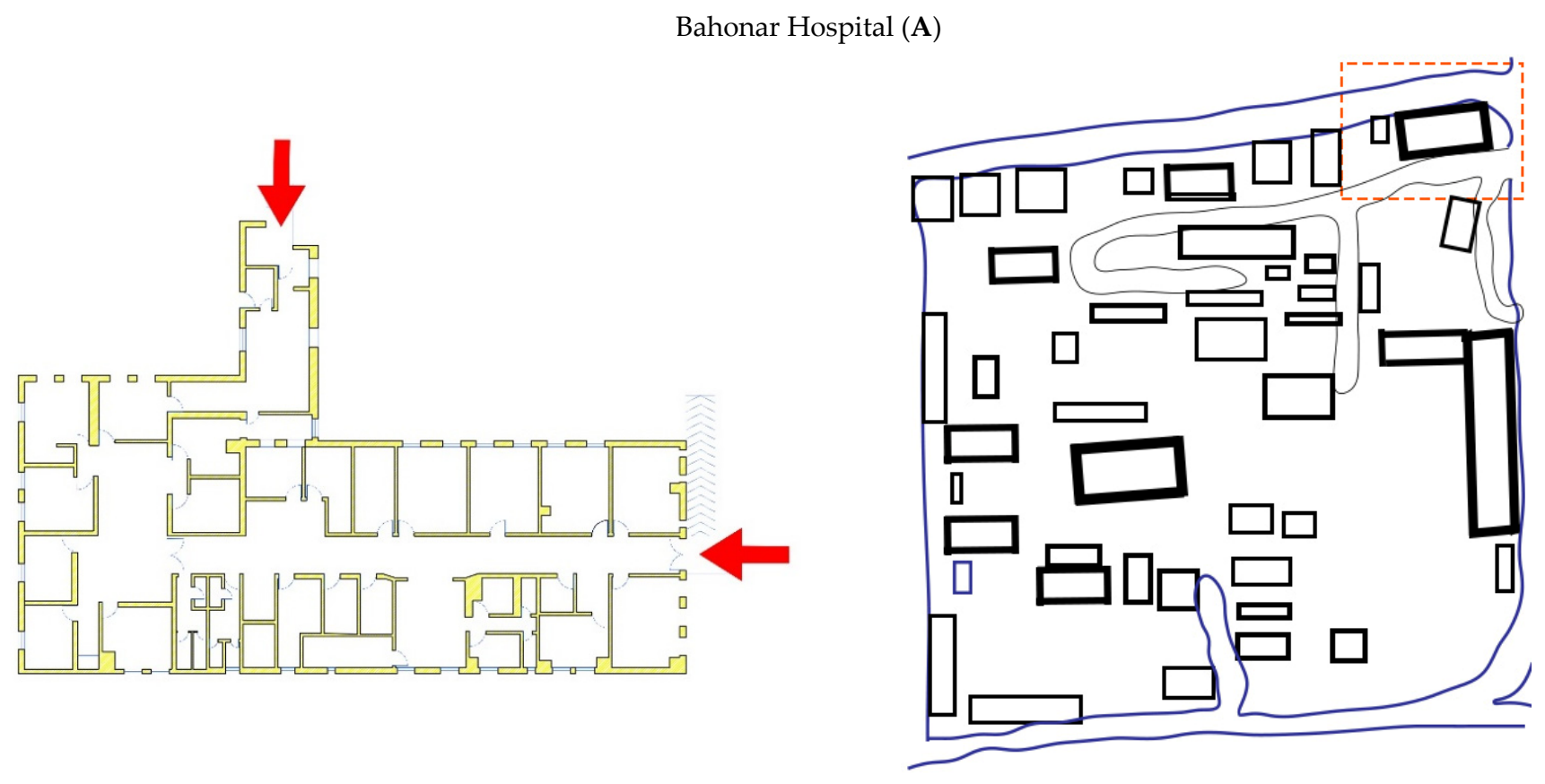

Figure 1. Cont. 
Afzalipour Hospital (B)

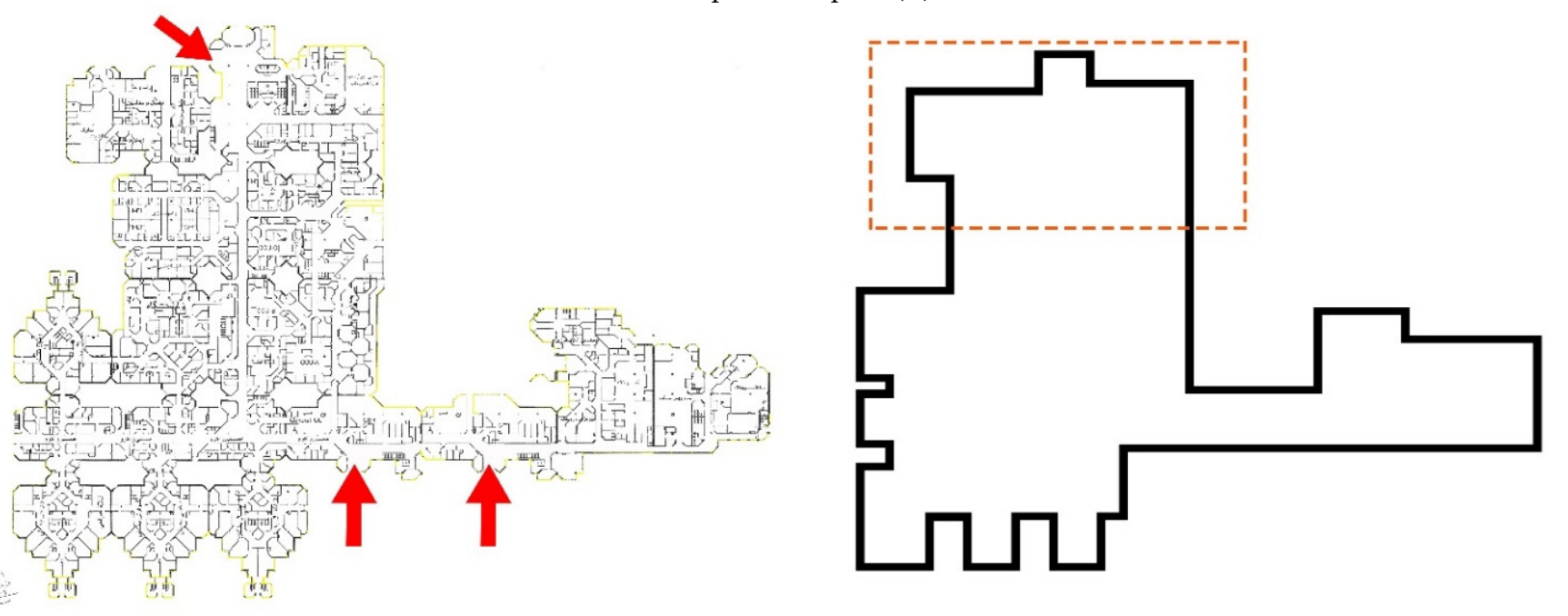

Mehregan Hospital (C)
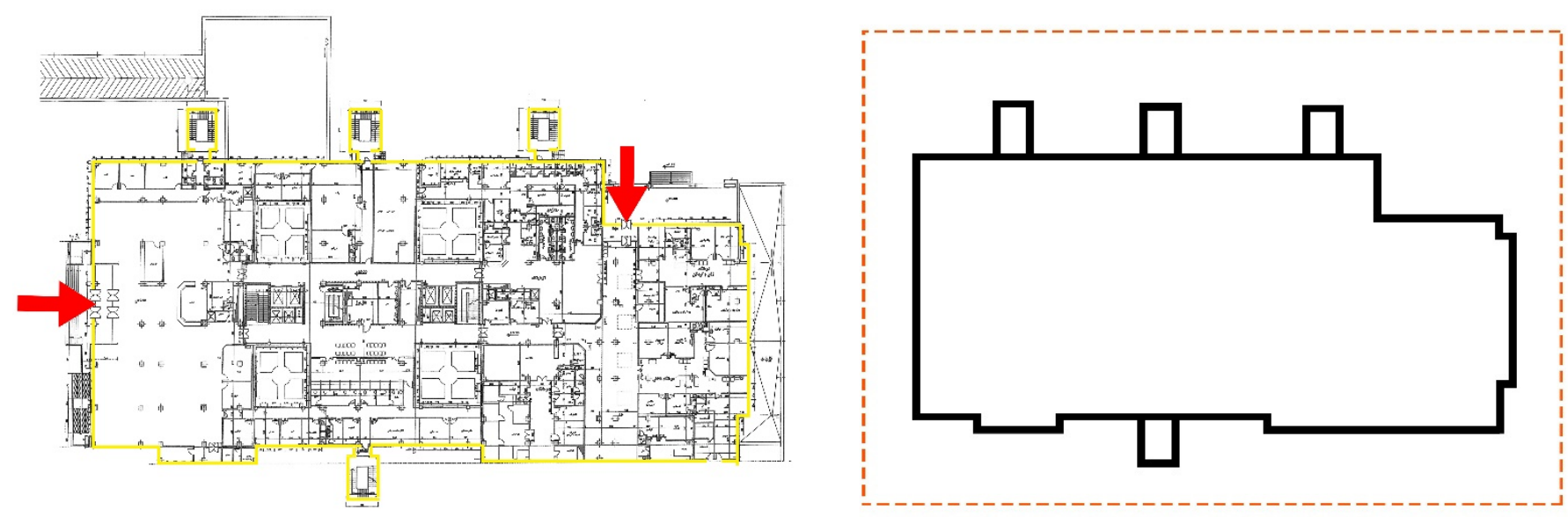

Payambar Azam Hospital (D)
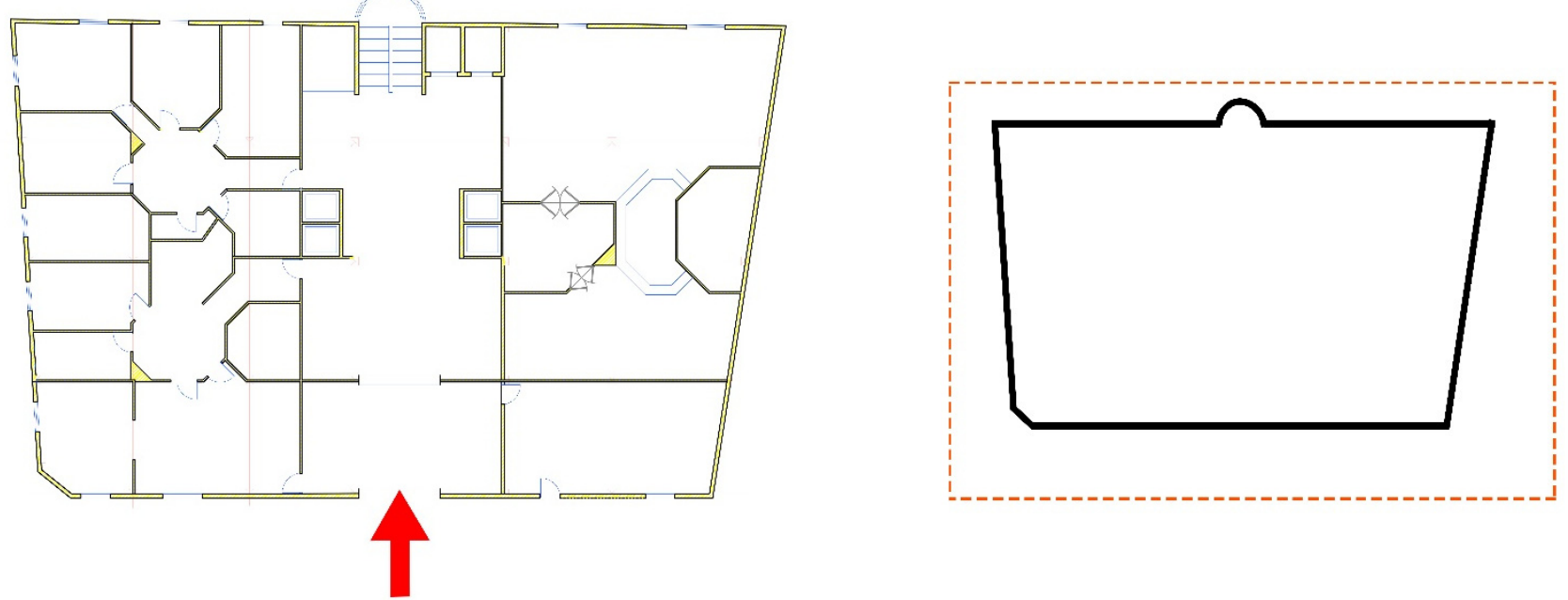

Figure 1. Left: the building layouts of the studied hospitals. Right: the COVID-19 patient admission area in each hospital. 


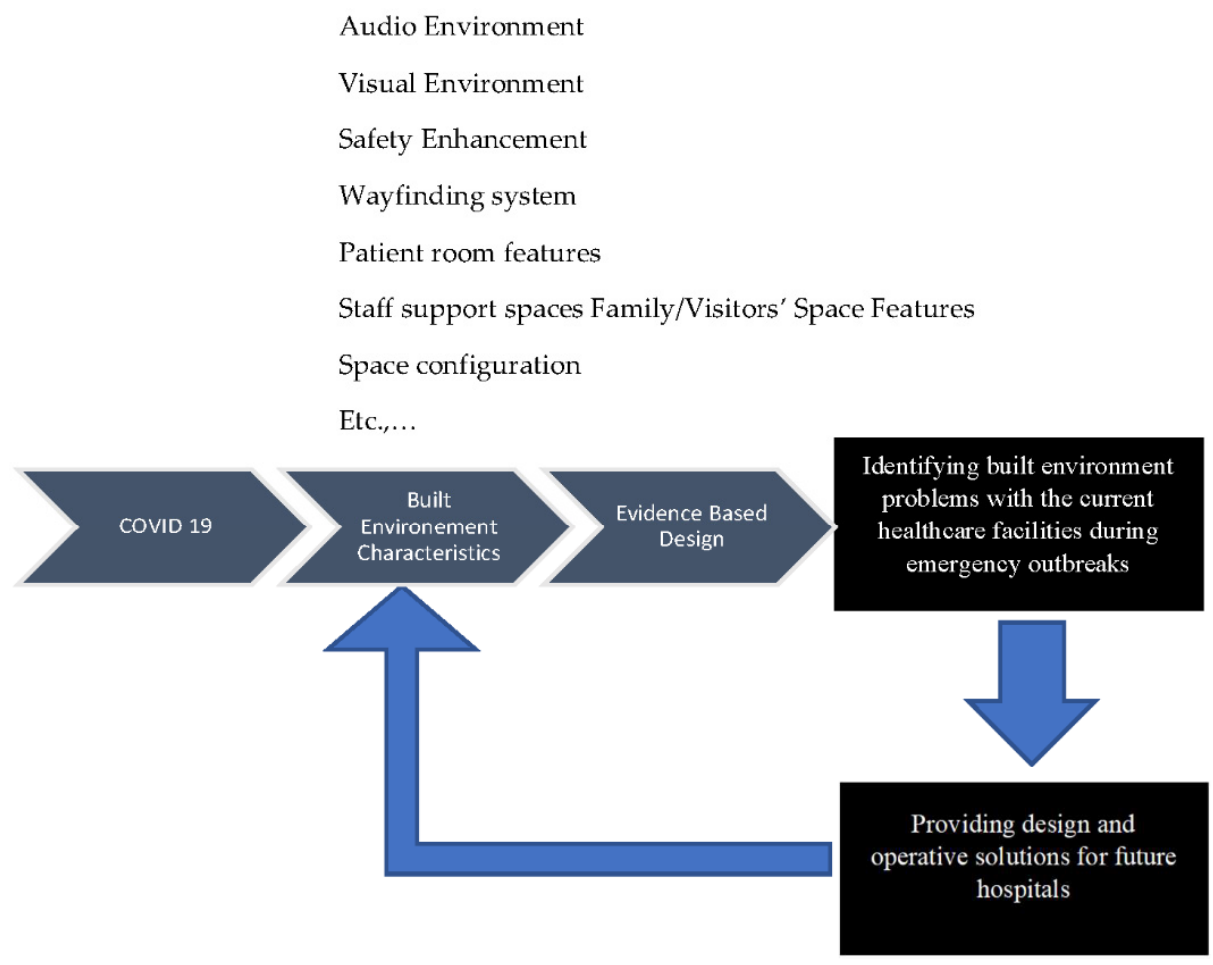

Figure 2. The proposed framework for the study.

\section{Identified Problems}

\subsection{Space Configuration for the Hospitalization of Patients}

\subsubsection{Poor Isolation of the Infectious Ward}

The infectious ward was one of the most essential parts of the hospital that was widely used during the COVID-19 outbreak. However, there were no filter areas between the infectious ward and the other sections, and it was only separated from the other areas by a single door. Most of the participants argued that this section should have been properly isolated from the other sections. Separating this section from the main hall with only one door was of great concern since the door was left open most of the time. For this reason, the probability of coronavirus transmission from the coronavirus ward to other wards and the hospital hall was high. Some doctors voiced their concerns about the risk of disease transmission associated with the poor design of hallways in one of the hospitals. One participant stated that: "The way to other wards passes through the infectious ward, and this is very risky". Many therapists suggested that reducing the risk of disease transmission requires some measurement in terms of isolation.

\subsubsection{Improper or Absence of Spatial Isolation of Patients with COVID-19 from Others}

There was a consensus on the special care needed for patients with COVID-19. In some hospitals, one of the intensive care units of the hospital was assigned to these patients. There was not much concern in hospitals where the intensive care unit was associated with patients with COVID-19.

The medical staff's concerns were related to the hospitals in which patients with COVID-19 were not adequately separated from the other patients or the fact that the intensive care units for patients with COVID-19 were in proximate distance to other sensitive wards (e.g., pediatric or gynecological). In these cases, the possibility of virus transmission to the sensitive wards increased. Regarding the limited capacity, patients with COVID-19 were reported to be admitted to the same wards where non-COVID 19 patients had been hospitalized. Some added that the beds were very close to each other, and patients with COVID-19 were not properly isolated from the non-COVID-19 patients. 
"Unfortunately, due to limited space and facilities, patients with COVID-19 and non-

COVID patients are in the same place, and only some beds for patients with COVID-19 have been isolated by a plastic cover".

Hospitals can lower the incidence of nosocomial infections (hospital-acquired infections) during COVID-19 by the appropriate separation of the infectious ward from the rest of the hospital system and by assigning intensive care units for patients with COVID-19. The presence of empty and support areas, known as "lung" spaces, among different wards provides a means for accommodating reconfigurations, expansions, or isolation areas [25].

\subsubsection{Long Distance between Essential Parts}

Nurses spend a lot of time engaging in unnecessary walking, which leads to a waste of valuable time and leads to fatigue and stress [7]. One effective way to reduce walking is to bring staff and necessary supplies closer to patients $[45,46]$. The excessive distance between the essential wards such as the ICU and the CT scan area was reported to be the medical staff's source of confusion and fatigue. Some complained that the distance the patients had to walk to reach the different sections of the hospital put health care workers at risk of being exposed to the virus. A participant working at one of the hospitals suggested that:

"The long-distance between some related wards makes us walk a lot every day. This is frustrating. There is a possibility of contaminating different wards of the hospital".

In the case of COVI-19, it is important to reduce the distance between essential wards to reduce unnecessary staff walking.

\subsection{Layout and Circulation of the Environment}

Circulation zones in hospitals are spaces that can be reached independently by the public who use the hospital. Such spaces include the area in front of the entrance, the entrance hall, reception areas, corridors, vertical connections, and waiting rooms [47]. However, according to health care workers, such places have a high risk for infection transmission.

4.2.1. Problems with the Main Entrance/Shared Entrance for the CT Scan and Lung Screening and the Inadequacy of Facilities

During the outbreak, one of the concerns for many health care workers was inappropriate entrance design. In most hospitals, the entrance was reported to be commonly used by both the medical staff and the patients with COVID-19. This lack of isolation created a high-risk environment. In some hospitals, the temperature and oxygen levels of all of the people entering the hospital were screened. One of the hospital staff pointed out that:

"The medical staff and patients and escorts have to enter the hospital from the same door, and apart from them, the staff has to take off their masks in the crowded entrance during the exit and entrance to be recognized."

"Unfortunately, there is just one door for patients and health workers. We cannot distinguish the patients from their appearance until the doctor examines them and sees if they are suffering from COVID-19. To go to the doctor's room, they have to use the entrance used by others and sit beside others, and the only thing that is being practiced is wearing masks."

"A separate entrance door is allocated to pregnant women."

"There are several side entrances to the hospital, but the lack of attention to proper signposts results in overcrowding in the main entrance."

As it can be seen in Figure 3, the highest risk of infection transmission occurs here, as health care workers, COVID-19 patients, and other patients share the same entrance. 


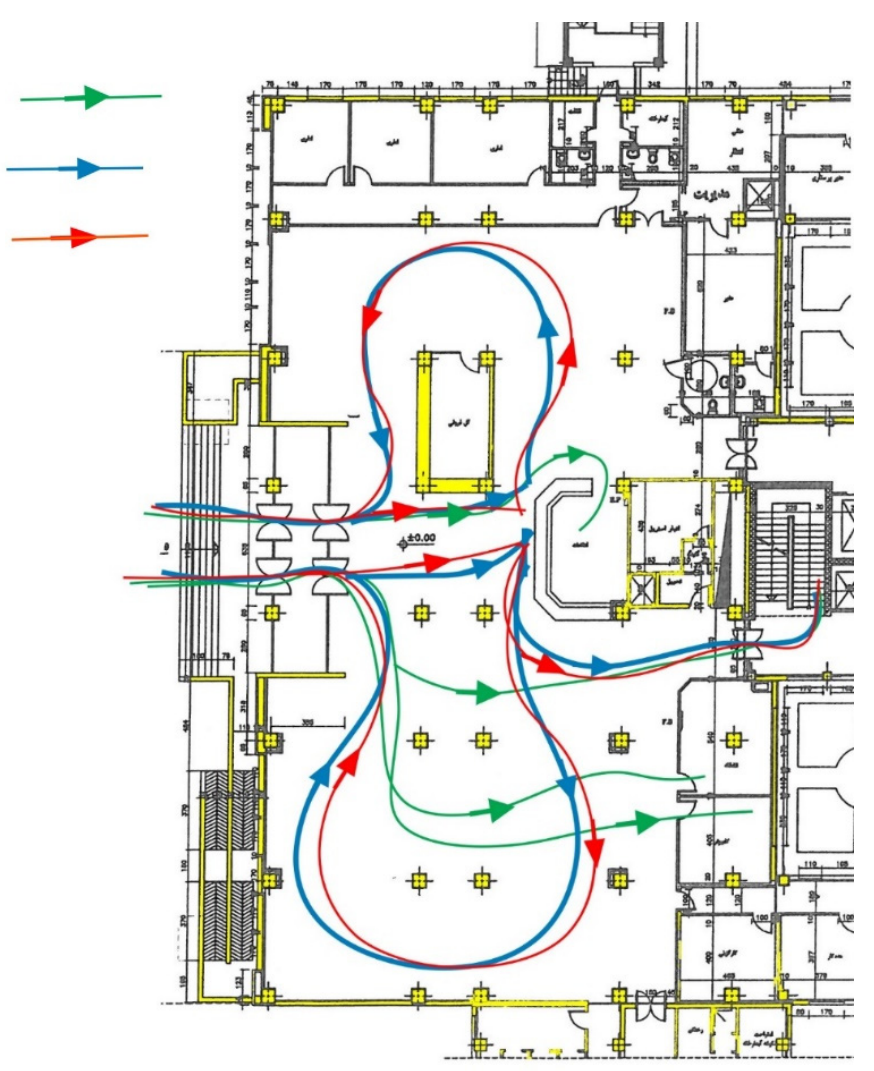

Figure 3. All patients share the same entrance (Mehregan Hospital).

The risk of transmitting the virus to other patients was reported to increase by insufficient CT scans. Transporting COVID-19 suspects and patients who have tested positive to the radiology department was of great concern. Some complained about the limited number of CT scan devices in the current situation and highlighted that this number did not meet the requirement in these critical conditions.

"This hospital is designed for treating cardiovascular patients. Though we treat lung patients, this hospital is not specifically designed for lung patients. The admission of a large number of patients with COVID-19 has posed a serious challenge to the hospital in recent months."

\subsubsection{Problems of the Emergency Department and Waiting Rooms}

The lack of a separate and dedicated space for the initial assessment of COVID-19 suspects and for the temporary hospitalization of in-patients was frequently reported by the health care workers. The absence of space for segregating COVID-19 suspects from the other patients in the emergency was nerve-wracking. The suspects were reported to stay in the emergency until their symptoms were checked. The COVID-19 positive patients were stated to be transferred to the infectious ward or were hospitalized away from other patients in the same emergency room. There was an agreement that this led to a greater prevalence of COVID-19. The health care workers highlighted that this problem was associated with the poor design of the emergency room. Some believed that patients were more likely to contaminate the area while they were being tested.

"Unfortunately, in the emergency section, all the patients are placed together until they are examined and referred to the relevant section. There are patients with COVID-19 and heart disease, etc."

Only in the emergency of one hospital was the test performed in a special room, for which there was a separate entrance. 
"Yes, fortunately, we have one special room for COVID patients. The protocols have been followed in this regard, the tests are performed in a special room within the emergency section."

From the perspectives of health care workers, one of the hospital design problems contributing to the spread of COVID-19 was the waiting room. Health care workers stated that in some of the hospitals, the waiting room for the patients was poorly designed. People had to stand in the corridors or wait in a small space where social distancing was not practiced. Some hospitals did not even have a waiting room. According to one of the staff members, the hall was very small and was poorly ventilated, and the arrangement of the chairs and the number of chairs had not changed even though the number of patients and their escorts had been on the rise.

"The waiting room is not suitable for hospitalization and admission of patients with COVID-19 because the waiting room is small, there is no natural ventilation, and the necessary distance cannot be observed at all."

4.2.3. Improper or Absence of Spatial Isolation of Communication Spaces and Transporting Patient Tested Positive

According to the health care workers, after screening patients in the emergency room, the patients with COVID-19 needed to be transferred to the hospital wards, CT scans, and intensive care sections of the hospital. However, there were no physically separated corridors for these patients, and they had to use the corridors and stairs shared by other people. The absence of spatial separation in communal spaces was reported to affect the spread of COVID-19.

"If the test is positive, a CT scan of the lungs should be done immediately in the infectious ward of the hospital. For a CT scan, patients and their escorts have to go to different parts. The doctor often asks the acute cases to be hospitalized. This cohort of patients is admitted to the third floor. Unfortunately, the location of this ward on the third floor has created problems because the patients need to use different corridors and communal spaces, and this expands the disease cycle."

The strong relationship between the CT scan, infectious wards, and intensive care units requires an appropriate space configuration that allows for the fast movements of both patients and health care workers.

\subsubsection{Lack of Sufficient Elevators}

The increasing number of patients was reported to result in a shortage of elevators. The common use of elevators by COVID-19 patients and their escorts were frequently highlighted as a major concern. A nurse suggested that:

"There are six elevators for ordinary people and three elevators for transporting patients in this hospital, of which one is supposed to be used for the patients with COVID-19. Overcrowding at the visiting time makes the patients' supporters (who have spent several hours directly with the sick person) use other elevators in this complex".

"There are three elevators for transporting regular patients, but since the time of breakout, we are facing a shortage of elevators. To reach the elevators, we have to go through the common corridors."

Cross-contaminations in hospitals could be minimized by isolating treatment spaces for COVID-19 patients through clear route separations and avoiding the use of horizontal and vertical circulations for multiple areas [25].

\subsection{Operation Services}

\subsubsection{Non-Segregation of Hospital Admission and Lack of Social Distancing Measures}

One of the most important problems in all hospitals is the admission of patients with COVID-19 along with other patients in one place. This was assumed to be the main cause 
of virus transmission. The medical staff reported that the restriction posed by the fixed desks and partitions did not let the staff and nurses maintain a distance of $1.5 \mathrm{~m}$ from each other. This was reported to increase the risk of infection among the medical staff.

"The problem with all hospitals is that the admission ward for COVID-19 has not been isolated from the other wards."

"The treatment staff can't move tables and partitions, and they have to be very close to each other and work in a small space."

\subsubsection{Improper Clothing Isolation and Disinfection of Equipment for} Non-COVID-19 Patients

Transferring the clothes and bedding of patients with COVID-19 along with those of non-COVID-19 patients to the same laundries and sterile rooms was a concerning issue. Some added that in some hospitals, though separate rooms were allocated for the clothing of patients with COVID-19, the clothes of patients with COVID-19 were washed with those of non-COVID19 patients together in the central laundry. Transferring all of the equipment used in all of the wards to one place without spatial separation was expected to result in the transmission of the disease to other staff or patients.

"This hospital has a central laundry, and it is not possible to separate and allocate a separate place for the stuff of patients with COVID-19, and all washing is done inside this place."

"All hospital equipment and supplies for the patients with COVID-19 and non-COVID19 patients need to be disinfected. The disinfection is carried out in a sterile room."

\subsubsection{Lack of Indoor Environmental Conditions/Improper Lighting}

Hospital lighting had been one of the most concerning issues in hospital design since the COVID-19 outbreak. Some doctors argued that poor lighting and low light in spaces such as hospital rooms, stairs, and corridors resulted in eye fatigue and allowed environmental pollution to go unnoticed by the cleaning staff. The stress on the medical staff, who were staying in a room without windows for long hours and who lacked chances to be outdoors intensified the mental pressure on the medical staff and the patients.

"There is not enough light in the rooms, and the height of the rooms is very low. I do not like to stay in hospital rooms for a long time. These spaces are too depressing."

\subsection{Organizational Support for Staff}

\subsubsection{Inadequate Resting Places for Medical Staff}

One of the main concerns repeatedly mentioned in the interviews was the inadequacy of the resting areas. Some complained that the areas in which the staff rested were shared with people in other wards. This put the health of the staff in jeopardy. Despite the fatigue and stress of the medical staff during the pandemic, there was no change in the quality and size of the medical staff's resting space compared to the past. According to the medical staff, the small size of the resting areas and the lack of proper ventilation and facilities (e.g., space for handwashing, personal wardrobes) and noise pollution caused by the proximity to the wards harmed the resting quality of health care workers. The poor quality of health care acoustics is a major environmental stressor that negatively impacts hospital occupants [44].

"The medical interns' and residents' resting area has few facilities, and there are 3-4 beds in each room. Since each one needs to be on call during the break, the ringing tone is of annoyance to others. It would be better for each person to have a separate room."

"There are six or eight people in a small room. Though each one needs to have his mask on, social distancing is not observed."

"The resting room is not separated from the ward. The nurses' resting room is inside the COVID-19 ward. The room is very crowded, and there are almost 10 beds in a small room." 


\subsubsection{Inappropriate Eating Conditions of Treatment Staff}

The staff dealing with patients with COVID-19 stated that they were under a lot of stress, and providing facilities for them was perceived to help them mitigate work stress.

In most hospitals, the self-service food outlets had been closed since the COVID-19 outbreak. The food had been a taken away, and they had to have their meals in the resting room or in their cars. Some health care workers complained about the annoying smell of the food and the poor nutrition of the health care workers in the hospital environment.

"Since the time of the outbreak, we have not been to the self-service restaurant in the hospital. I think each section should have a separate restaurant, and this area should have access to the terrace and special open space."

"The pantry is not close to the resting room and is near the place where there are lots of patients, and the risk of contamination is anxiety-provoking."

\subsubsection{Improper Separation of Sanitation Services}

One of the complaints of the health care personnel in some hospitals was the absence or improper separation of the medical staff's sanitation facilities (e.g., toilet, handwashing basin) from patients. Some reported that health care workers had to use the patient toilet services. Some complained that all sanitation services were placed in one area. The only way to isolate the health care worker sanitation facilities was by locking them.

"In surgery, intensive care, and infectious wards, the sanitation services of the medical staff and patients are separated from each other, but in the other wards, they are commonly used by patients. This makes the medical staff feel anxious."

Table 1 summarizes all the identified problems in the studied hospitals.

Table 1. The problem with the current hospitals can be summarized as above.

\section{The Built Environment and Its \\ Impact on Health Outcomes and Experiences of Staff during COVID-19}

Lack of supportive environmental factors to minimize hospital-acquired infections

Space configuration

Shared Facilities between

Lack of operation strategies

Lack of organization support Visual comfort measures Staff resting rooms Staff dining spaces

\section{Built Environment Design Variables}

\section{Main Problems}

Problems with COVID-19 patients and others sharing the main entrance

Layouts and circulations COVID-19 and other patients Social Distancing Sanitation facilities
Problems with the emergency department and waiting rooms

Improper spatial isolation of communal spaces and transporting patients who have tested positive through horizontal and vertical circulation Poor isolation of the infectious ward Improper or absence of spatial isolation of patients with COVID-19 from others

Long distance between essential parts of the hospital Improper clothing isolation and disinfection of equipment for non-COVID-19 patients

Lack of improper lighting/ lack of windows Inadequate resting places

Inappropriate eating conditions of treatment staff Lack of social distancing in staff rooms and fixed furniture

Improper separation of sanitation services

\section{Discussion}

The design of health care buildings has evolved during history to fit into the demands of the healing process. Health care design refers to the physical environment that includes the interior design (e.g., furniture, fixtures, and materials), the configuration (e.g., relative 
locations and adjacencies of spaces), and the indoor environment (e.g., noise, air quality, and lighting) of a hospital [7].

The emergence of the COVID-19 pandemic in 2019 highlighted the importance of hospital design in a health care space. It further brought about the importance of infection control in health care environments. While COVID-19 brought several challenges, enhancing health care worker and patient safety during the pandemic has not been very well integrated into the design aspects of hospital buildings [48].

Compared to all of the countries involved in combating the pandemic, Iran has faced one of the worst COVID-19 outbreaks in the world [49] and has had one of the highest mortality rates of medical staff from COVID-19 [50]. Iran's initially ineffective response to the pandemic can be explained in terms of weakness in economic policy, failure to coordinate public health initiatives, priority of treatment over prevention, insufficient public engagement, and inadequate health care facilities [51]. Factors such as the imposed sanctions have challenged Iran's ability to cope with COVID-19. Some essential medicine and laboratory equipment (such as diagnostic and protection kits) were not adequately available during the outbreak due to complications in financial exchanges with most countries [52]. Many health care workers have been risking their lives working under unsafe and extremely stressful conditions. The health care staff has faced two significant concerns during the pandemic: to treat patients with severe symptoms and to prevent the spread of the virus among themselves and other patients.

Due to the importance of infection control in health care environments and the rising number of COVID-19 patients, the current study identified contradictions in the health care environment in terms of infection control during a pandemic in four different hospitals in Kerman city, Iran, focusing on the experiences of health care workers.

The result of the study indicated that the hospitalization of patients the workplace of the health care workers, the layout and circulation of the environment, the conditions of the indoor environment, and the operation and maintenance of health care systems were the most important factors affecting infection control in health care environments. The study also shed light on the fact that the gap between the safety needs of health care workers and the implementation of actual solutions during the COVID-19 pandemic is wide.

Moreover, a deep examination of health care worker responses revealed that the majority of infection control barriers are rooted in the mutual admission and hospitalization of COVID-19 patients with other patients. One of the key aspects to consider within the functional program in relation to pandemics is the circulation in health care environments. The staff, visitors, and patients who are not directed to the emergency department must have their unique access. Flows that are typically differentiated between users and health care workers must be further separated during emergencies to divide the flows of patients with suspected or known infection from the other patients. Similarly, the staff working in infection wards should not share facilities (dining area, toilets) with the other health care workers. Supposing the physical layout and space management of health care centers can minimize or increase the risk of infectious disease transmission. In that case, the following question arises regarding various hospital design layouts: which layout might be better suited for pandemic situations? A deep examination of health care workers reveals that the isolation and separation of COVID-19 patients from the others at the entrance might be the best solution. Based on EBD, Ulrich et al. [35] provided evidence related to design factors that reduced the frequency of acquired infections in hospitals. The factors include implementing single-bed rooms, effective air quality control, the placement of alcohol-based hand-run dispensers, clean surfaces and floors, and proper water systems designed to minimize water stagnation. However, the implementation of some of these guidelines might not be possible during a pandemic crisis. For example, during the COVID19 outbreak, it has been hard to designate a separate room for COVID-19-infected Patients. Crowded and poorly ventilated indoor environments represent more significant risks of exposure to potentially infectious droplet nuclei and viral transmission $[1,53]$. Separating 
the COVID-19 section of hospitals can make ventilation much more efficient and easier to implement.

The building plans examined in this study were:

1. Several single and double-story linear scattered buildings in the hospital yard.

2. A multi-story clustered plan.

3. A linear multi-story plan.

4. A square multi-story plan.

The health care workers shared fewer concerns for infection transmission in the clustered plan layout (Afzalipour Hospital). Since clustered building plans have the highest potential for the zoning and isolation of COVID-19 patients from others, they imposed less stress among the health care staff. However, Afzalipour Hospital also has several shortcomings. The WHO guidelines for infection control during pandemics have not been fully implemented even in this hospital; for example, in most cases, all patients are admitted to the emergency sector upon arrival. There is no filter at the entrance to separate COVID-19-infected patients from other patients. COVID-19-infected patients and the other patients also share circulation zones such as the entrance hall, reception areas, corridors, vertical connections, and waiting rooms, maximizing the risk of hospitalacquired infections for the other patients and the staff. Due to the sudden surges of patients, some medical spaces, such as the CT scan and intensive care sections (ICU), are shared among infected patients and other patients (it is not easy to convert standard patient rooms to ICU rooms), increasing the risk of infection. Accordingly, the least risky decision for infection control in health care environments during pandemics might be the complete separation of COVID-19-infected patients from the other patients admitted to the hospital. Scattered building layouts also allow for a complete separation of infected patients from other patients (such as Bahonar Hospital). Another possible solution is to design health care facilities with a flexible approach, where the layouts can transform rapidly to meet the demands of both pandemics and permanent conditions. The use of modular architecture that can be adapted during pandemics is one possible solution. The design of multiple entrances, multiple staircases, and multiple elevators that can further separate a building section or a building floor (in multi-story buildings) during pandemics are other possible solutions for hospital design in the future. Meanwhile, health care facilities in both cases must design adequate infrastructure that supports the conversion of existing spaces into temporary ones; for example, standard patient rooms into ICUs or conference rooms into treatment spaces.

Each of the discussed infection control measures substantially adds to the capital and operating expenses of health care facilities. Building better designed health care facilities from scratch, ideally with scattered layouts, will likely be costly and timely to operate. Reorganizing existing health care spaces that allow for the separation of COVID19 patients from others is likely to be cheaper. Still, it may require relatively expensive improvements to entrances, circulations (horizontal and vertical), ventilation, etc. The designation of specific hospitals for COVID-19 patients seems to be an effective and relatively inexpensive improvement. However, allocating some hospitals as a reception center for COVID-19 patients may not always be possible due to the financial barriers they face. The hospitalization of COVID-19 patients imposes additional costs to private health care centers and hospitals and reduces their income due to the cancellation of elective surgeries [54]. Further studies may conduct empirical research on the economic evaluation of the required infrastructure costs in public hospitals needed to use resources during pandemics efficiently. According to the World Health Organization (WHO), sustainability in health care systems can be achieved when resources are used as effectively as possible to benefit the health and well-being of current and future generations. The design and organization of space and resilient and adaptive hospital layouts can significantly impact health care sustainability through their efficiency during pandemics.

There are some limitations in this research. The case studies were limited to four hospitals in Kerman. It is likely that the other public and private hospitals in the country 
face different environmental contradictions in terms of infection control. The online survey method limited responses to those who could use a computer and who had internet access. Face to face encounters with the staff would have enriched the possibility for more equally inclusive and accurate research. The high risk of contamination in the hospitals was an obstacle to conducting structured observations in the wards. Future research may address these. Ultimately, while the COVID-19 pandemic will end as previous pandemics have, it is evident that it will not be the last. Therefore, lessons learned from this research can help design and manage resilient hospitals to deal with future pandemics.

Author Contributions: Conceptualization, M.L. and F.K.; methodology, F.K.; validation, M.L., F.K. and M.J.K.; formal analysis, F.K.; investigation, M.S.N.; resources, M.L.; data curation, M.S.N.; writing-original draft preparation, F.K. and M.L.; writing—review and editing, M.L and M.J.K.; visualization, M.S.N.; supervision, M.J.K.; project administration, F.K. All authors have read and agreed to the published version of the manuscript.

Funding: This research received no external funding.

Institutional Review Board Statement: This research was conducted independently without funding or support from any institution. Interviewees voluntarily participated in the study, were informed prior to interviews about the aims of the research, and were given anonymity across the process and in the write-up. Researchers obtained verbal consent from each interviewee prior to the interviews, and no harm or duress were inflicted on interviewees.

Data Availability Statement: Informed consent was obtained from all subjects involved in the study.

Acknowledgments: We would like to thank all the health care staff of the Afzalipour, Bahonar, Payambar Azam, and Mehregan Hospitals for their kind participation in our research.

Conflicts of Interest: The authors declare no conflict of interest.

\section{References}

1. La Rosa, G.; Fratini, M.; Della Libera, S.; Iaconelli, M.; Muscillo, M. Viral infections acquired indoors through airborne, droplet or contact transmission. Ann. Ist. Super Sanita 2013, 49, 124-132. [CrossRef]

2. WHO. How Is Covid 19 Transmitted? World Health Organization, 2020. Available online: https://www.who.int/vietnam/news / detail/14-07-2020-q-a-how-is-covid-19-transmitted (accessed on 21 March 2021).

3. CDC. Scientific Brief: SARS-COv-2 and Potential Airborne Transmission. Centers for Disease Control and Prevention. Available online: http:/ / en.sbmu.ac.ir/uploads/201007_-_Scientific_Brief_SARS-CoV-2_and_Potential_Airborne_Transmission__C DC.pdf (accessed on 21 March 2021).

4. Reason, J. Human error: Models and management. BMJ 2000, 320, 768-770. [CrossRef] [PubMed]

5. Ulrich, R.S.; Wilson, P. Evidence-based design for reducing infection. Public Serv. Rev. Health 2006, 8, $24-25$.

6. Haq, S.; Luo, Y. Space syntax in healthcare facilities research: A review. HERD 2012, 5, 98-117. [CrossRef]

7. Joseph, A.; Rashid, M. The architecture of safety: Hospital design. Curr. Opin. Crit. Care 2007, 13, 714-719. [CrossRef]

8. Raoofi, A.; Takian, A.; Akbari Sari, A.; Olyaeemanesh, A.; Haghighi, H.; Aarabi, M. COVID-19 pandemic and comparative health policy learning in Iran. Arch. Iran. Med. 2020, 23, 220-234. [CrossRef]

9. Vindrola-Padros, C.; Andrews, L.; Dowrick, A.; Nehla Djellouli, H.F.; Bautista Gonzalez, E.; Javadi, D.; Lewis-Jackson, S.; Manby, L.; MItchinson, L.; Mulcahy Simmons, S.; et al. Perceptions and experiences of healthcare workers during the COVID-19 pandemic in the UK. BMJ Open 2020, 10, e040503. [CrossRef]

10. Abbas, S.; Al-Abrrow, H.; Abdullah, H.O.; Alnoor, A.; Khattak, Z.Z.; Khaw, K.W. Encountering Covid-19 and perceived stress and the role of a health climate among medical workers. Curr. Psychol. 2021. Online ahead of print. [CrossRef]

11. Sun, N.; Wei, L.; Shi, S.; Jiao, D.; Song, R.; Ma, L.; Wang, H.; Wang, C.; Wang, Z.; You, Y.; et al. A qualitative study on the psychological experience of caregivers of COVID-19 patients. Am. J. Infect. Control 2020, 48, 592-598. [CrossRef] [PubMed]

12. Liu, Q.; Luo, D.; Haase, J.E.; Guo, Q.; Wang, X.Q.; Liu, S.; Xia, L.; Liu, Z.; Yang, J.; Yang, B.X. The experiences of healthcare providers during the COVID-19 crisis in China: A qualitative study. Lancet Glob. Health 2020, 8, e790-e808. [CrossRef]

13. Song, X.; Fu, W.; Liu, X.; Luo, Z.; Wang, R.; Zhou, N.; Yan, S.; Lv, C. Mental health status of medical staff in emergency departments during the coronavirus disease 2019 epidemic in China. Brain Behav. Immun. 2020, 88, 60-65. [CrossRef]

14. Kieft, R.A.; de Brouwer, B.B.; Francke, A.L.; Delnoij, D.M. How nurses and their work environment affect patient experiences of the quality of care: A qualitative study. BMC Health Serv. Res. 2014, 14, 249. [CrossRef]

15. Aiken, L.H.; Sermeus, W.; Van den Heede, K.; Sloane, D.M.; Busse, R.; McKee, M.; Bruyneel, L.; Rafferty, A.M.; Griffiths, P.; Moreno-Casbas, M.T.; et al. Patient safety, satisfaction, and quality of hospital care: Cross sectional surveys of nurses and patients in 12 countries in Europe and the United States. BMJ 2012, 344, e1717. [CrossRef] [PubMed] 
16. Kutney-Lee, A.; McHugh, M.D.; Sloane, D.M.; Cimiotti, J.P.; Flynn, L.; Neff, D.F.; Aiken, L.H. Nursing: A key to patient satisfaction. Health Aff. 2009, 28, w669-w677. [CrossRef] [PubMed]

17. McHugh, M.D.; Kutney-Lee, A.; Cimiotti, J.P.; Sloane, D.M.; Aiken, L.H. Nurses' widespread job dissatisfaction, burnout, and frustration with health benefits signal problems for patient care. Health Aff. 2011, 30, 202-210. [CrossRef] [PubMed]

18. Al Thobaity, A.; Alshammari, F. Nurses on the Frontline against the COVID-19 Pandemic: An Integrative Review. Dubai Med. J. 2020, 3, 87-92. [CrossRef]

19. Aygün, G.; Demirkiran, O.; Utku, T.; Mete, B.; Urkmez, S.; Yilmaz, M.; Yaşar, H.; Dikmen, Y.; Oztürk, R. Environmental contamination during a carbapenem-resistant Acinetobacter baumannii outbreak in an intensive care unit. J. Hosp. Infect. 2002, 52, 259-262. [CrossRef]

20. Boyce, J.M.; Potter-Bynoe, G.; Chenevert, C.; King, T. Environmental contamination due to methicillin-resistant Staphylococcus aureus possible infection control implications. Infect. Control Hosp. Epidemiol. 1997, 18, 622-627. [CrossRef] [PubMed]

21. Huisman, E.R.C.M.; Morales, E.; van Hoof, J.; Kort, H.S.M. Healing environment: A review of the impact of physical environmental factors on users. Build. Environ. 2012, 58, 70-80. [CrossRef]

22. Pangrazio, J.R. Planning Public Spaces for Health Care Facilities. Health Facilities Management. Available online: http:/ / www.hfmmagazine.com/display/HFM-newsarticle.dhtml?dcrPath/templatedata/HF_Common/NewsArticle/d ata/HFM/Magazine/2013/Mar/313HFM_FEA_design (accessed on 13 January 2013).

23. Jiang, S.; Verderber, S. On the Planning and Design of Hospital Circulation Zones. HERD 2017, 10, 124-146. [CrossRef]

24. Brambilla, A.; Rebecchi, A.; Capolongo, S. Evidence based hospital design. A literature review of the recent publications about the EBD impact of built environment on hospital 'occupants' and organizational outcomes. Ann. Ig. 2019, 31, 165-180.

25. Capolongo, S.; Gola, M.; Brambilla, A.; Morganti, A.; Mosca, E.I.; Barach, P. COVID-19 and Healthcare facilities: A decalogue of design strategies for resilient hospitals. Acta Bio. Med. 2020, 91, 50-60.

26. Ulrich, R.S. View Through a Window May Influence Recovery from Surgery. Science 1984, 224, 420-421. [CrossRef]

27. Nejati, A.; Shepley, M.; Rodiek, S.; Lee, C.; Varni, J. Restorative Design Features for Hospital Staff Break Areas: A Multi-Method Study. HERD 2016, 9, 16-35. [CrossRef] [PubMed]

28. Debajyoti, P.; Harvey, T.; Barach, P. The impact of exterior views on nurse stress: An Exploratory Study. Health Environ. Res. Des. J. 2008, 2, 27-38.

29. Bedon, C.; Mattei, S. Facial Expression-Based Experimental Analysis of Human Reactions and Psychological Comfort on Glass Structures in Buildings. Buildings 2021, 11, 204. [CrossRef]

30. Lateef, F. Hospital design for better infection control. J. Emergencies Trauma Shock 2009, 2, 175. [CrossRef]

31. Urlich, R.; Zimring, C.; Quan, X.; Joseph, A.; Choudhary, R. The Role of the Physical Environment in the Hospital of the 21st Century; The Center for Health Design: Concord, CA, USA, 2004.

32. Menzies, D.; Fanning, A.; Yuan, L.; FitzGerald, J.M. Hospital ventilation and risk for tuberculous infection in Canadian health care workers. Ann. Intern. Med. 2000, 133, 779-789. [CrossRef]

33. Anderson, R.L.; Mackel, D.C.; Stoler, B.S.; Mallison, G.F. Carpeting in hospitals: An epidemiological evaluation. J. Clin. Microbiol. 1982, 15, 408-415. [CrossRef]

34. Noskin, G.A.; Bednarz, P.; Suriano, T.; Reiner, S.; Peterson, L.R. Persistent contamination of fabric-covered furniture by vancomycin-resistant enterococci: Implications for upholstery selection in hospitals. Am. J. Infect. Control 2000, 28, 311-313. [CrossRef] [PubMed]

35. Ulrich, R.S.; Zimring, C.; Zhu, X.; DuBose, J.; Seo, H.-B.; Choi, Y.-S.; Quan, X.; Joseph, A. A review of the research literature on evidence-based healthcare design. HERD 2008, 1, 61-125. [CrossRef]

36. Alfonsi, E.; Capolongo, S.; Buffoli, M. Evidence Based Design and healthcare: An unconventional approach to hospital design. Ann Ig. 2014, 26, 137-143. [CrossRef] [PubMed]

37. Marberry, S.O. Improving Healthcare with better Building Design; Health Administration Press: Chicago, IL, USA, 2006.

38. Emmanuel, U.; Osondu, E.D.; Kalu, K.C. Architectural design strategies for infection prevention and control (IPC) in health-care facilities: Towards curbing the spread of Covid-19. J. Environ. Health Sci. Eng. 2020, 18, 1699-1707. [CrossRef] [PubMed]

39. Hockberger, P. The damaging effects of sunlight on bacteria. J. Photochem. Photobiol. 2000, 58, 155-191. [CrossRef]

40. Strong, P. Daylight Benefit in Healthcare Buildings. Designing Buildings-BR Group. 2020. Available online: https://www.design ingbuildings.co.uk/w/images/2/22/David_Strong_(2of2)Daylight_Benefits_in_Healthcare_buildgs-BRGroup (accessed on 23 April 2021).

41. Hamilton, D.K. The four levels of evidence-based practice. Healthc. Des. 2003, 11, 19-26.

42. Elf, M.; Anåker, A.; Marcheschi, E.; Sigurjónsson, Á.; Ulrich, R.S. The built environment and its impact on health outcomes and experiences of patients, significant others and staffs' protocol for a systematic review. Nurs. Open 2020, 7, 895-899. [CrossRef] [PubMed]

43. Strauss, A.L.; Corbin, J.M. Basics of Qualitative Research: Techniques and Procedures for Developing Grounded Theory, 2nd ed.; Sage: Thousand Oaks, CA, USA, 1998.

44. Ulrich, R.S.; Berry, L.L.; Quan, X.; Parish, J.T. A conceptual framework for the domain of evidence-based design. HERD 2010, 4, 95-114. [CrossRef]

45. Shepley, M.M. Predesign and post occupancy analysis of staff behavior in a neonatal intensive care unit. Child. Health Care 2002, 31, 237-253. [CrossRef] 
46. Shepley, M.M.; Davies, K. Nursing unit configuration and its relationship to noise and nurse walking behavior: An AIDS/HIV unit case study. AIA Acad. J. 2003, 6, 12-14.

47. Setola, N.; Borgianni, S. Designing Public Spaces in Hospitals; Routledge: New York, NY, USA, 2016.

48. Dickerman, K.N.; Barach, P. Designing the Built Environment for A Culture and System of Patient Safety-A Conceptual, New Design Process. In Advances in Patient Safety: New Directions and Alternative Approaches; Henriksen, K., Battles, J.B., Keyes, M.A., Grady, M.L., Eds.; Agency for Healthcare Research and Quality (US): Rockville, MD, USA, 2008; Volume 2.

49. Maarefvand, M.; Hosseinzadeh, S.; Farmani, O.; Safarabadi Farahani, A.; Khubchandani, J. Coronavirus outbreak and stress in Iranians. Int. J. Environ. Res. Public Health 2020, 17, 4441. [CrossRef]

50. Hamshahrionline. Available online: https://www.hamshahrionline.ir/news/531134/ (accessed on 1 March 2021).

51. Sajadi, H.; Hartley, K. COVID-19 pandemic response in Iran: A dynamic perspective on policy capacity. J. Asian Public Policy 2021. [CrossRef]

52. Rassouli, M.; Ashrafizadeh, H.; Shirinabadi Farahani, A.; Akbari, M.E. COVID-19 Management in Iran as One of the Most Affected Countries in the World: Advantages and Weaknesses. Front. Public Health 2020, 8, 510. [CrossRef] [PubMed]

53. Myatt, T.A.; Johnston, S.L.; Zuo, Z.; Wand, M.; Kebadze, T.; Rudnick, S.; Milton, D.K. Detection of airborne rhinovirus and its relation to outdoor air supply in office environments. Am. J. Respir. Crit. Care Med. 2004, 169, 1187-1190. [CrossRef]

54. Roshanzadeh, M.; Jamalinik, M.; Hasheminik, M.; Tajabadi, A. Stigma of Covid-19: The Basic Challenge in Health Economics. Iran Occup. Health 2020, 17 (Suppl. 1), 137-141. 